\title{
RELAÇÃO ENTRE AS VARIAÇÕES DA LINHA DE COSTA E AS CARACTERÍSTICAS MORFODINÂMICAS DA PRAIA DA ARMAÇÃO, ILHA DE SANTA CATARINA
}

\author{
RELATION BETWEEN THE VARIATIONS OF THE SHORELINE AND THE MORPHODYNAMIC \\ FEATURES OF ARMAÇÃO BEACH, SANTA CATARINA ISLAND
}

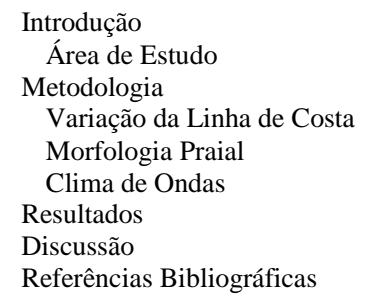

Anna Luiza Pacheco DALBOSCOํㅜ, Rodrigo do Carmo BARLETTA ${ }^{2}$, Davide FRANCO ${ }^{1}$

${ }^{1}$ Departamento de Engenharia Sanitária e Ambiental. Laboratório de Hidráulica Marítima. Universidade Federal de Santa Catarina. End: Servidão Eusébia Vidal - Carvoeira, Florianópolis - SC, 88040-370. Email: aldalbosco@gmail.com; d.franco.ocean@gmail.com ${ }^{2}$ Empresa Aster Engenharia. Email: barleta@ astergeo.com.br

RESUMO - A Praia da Armação, localizada no sudeste de Ilha de Santa Catarina, vem sofrendo nas últimas décadas um intenso processo erosivo em especial no setor central e sul da enseada. O objetivo deste estudo foi verificar a relação entre as taxas de retração e progradação da linha de costa da Praia da Armação e suas características morfológicas e padrões hidrodinâmicos. Foi realizado estudo de variação da linha de costa com imagens aéreas de 1977, 1994, 2002 e 2009, e foi aplicado um modelo de perfil de equilíbrio em planta. Como caracterização morfológica foi levantada a granulometria em 5 pontos ao longo da enseada e 10 perfis praiais subaéreos em 2 períodos distintos. E, a partir de 30 anos (1980 - 2009) de dados de reanálise de ondas, caracterizou-se o clima de ondas atuantes na região nas últimas três décadas. Os resultados deste estudo indicaram que existe uma relação entre as características morfodinâmicas da Praia da Armação e suas taxas históricas de variação da linha de costa. Porém, se verifica uma perda líquida de sedimentos ao longo do tempo, que possivelmente resulta da combinação entre fatores antrópicos (intensa ocupação urbana e o molhe no setor sul da praia) e naturais (aumento na ocorrência de condições hidrodinâmicas de alta energia).

Palavras-chave: variação de linha de costa, clima de ondas, morfodinâmica praial.

\begin{abstract}
Armação Beach, located in the southeast of Santa Catarina Island, has suffered in the last decades an intense erosive process especially in the central sector and south of the beach. The objective of this study was to verify the relationship between the retraction and progradation rates of Armação Beach shoreline and its morphological characteristics and hydrodynamic patterns. A study of coastline variation was performed using aerial images from 1977, 1994, 2002 and 2009, and was appied a model of equilibrium plan form. As a morphological characterization, the granulometry was collected in 5 points along the cove and 10 subaerial beach profiles in 2 different periods. And, from 30 years (1980 - 2009) of wave reanalysis data, we characterized the wave climate in the region in the last three decades. The results of this study indicated that there is a relationship between the morphodynamic characteristics of Armação Beach and its historical rates of shoreline variation. However, there is a net loss of sediment over time, possibly resulting from the combination of anthropogenic factors (intense urbanization and the groing in the south of the beach) and natural (increase in the occurrence of high hydrodynamic conditions energy).

Key words: shoreline change, wave climate, beach morphodynamic.
\end{abstract}

\section{INTRODUÇÃO}

As praias arenosas oceânicas constituem um dos ambientes mais dinâmicos da superfície do planeta, cujos depósitos sedimentares são retrabalhados por ondas, correntes e marés (Short, 1999). No Brasil, os processos de erosão ocorrem ao longo de toda a costa com predomínio sobre os processos de acresção (Muehe, 2006). A Ilha de Santa Catarina, assim como o território nacional, também vem sofrendo processos erosivos em diversas praias de sua orla (Abreu de Castilhos, 1995, 1997, 2010; Abreu de Castilhos et al., 2005; Mazzer et al., 2008; Rudorff \& Bonetti, 2010). A Praia da Armação foi classificada como de alto risco a processos erosivos em casos de eventos de ressaca, sendo que no setor sul foram encontrados os maiores valores de suscetibilidade (Mazzer et al., 2008; Rudorff \& Bonetti, 2010; Simó \& Horn Filho, 2004). Fato resultante pelo setor apresentar o perfil mais baixo e plano de toda enseada e por suas dunas frontais e interiores terem sido totalmente suprimidas pela urbanização. É discutido que a ampliação dos processos erosivos na praia pode estar associada não somente com o impacto da urbanização da orla e do balanço sedimentar longitudinal, mas também com o aumento na frequência e intensidade de eventos excepcionais de alta energia na região, decorrentes de oscilações climáticas.

$\mathrm{O}$ mais recente e intenso processo erosivo ocorrido na Praia da Armação aconteceu em abril de 2010 durante um evento de "ressaca", quando 
um ciclone extratropical no oceano deu início a fortes ventos do quadrante S/SE. Nos três meses que seguiram, sucessivos eventos de alta energia de onda associados a elevada maré meteorológicas chegaram a praia, erodindo o setor sul e central e atingindo mais de 70 casas. A Prefeitura de Florianópolis então decretou estado de emergência e iniciou obra de enrocamento na porção sul e central da praia. A obra possui 1,6 km de extensão e em torno de 84 mil metros cúbicos de pedras. Em 2013 a obra foi reformada com o objetivo de revitalizar a região e a tornar mais agradável para moradores e turistas. Atualmente, os órgãos públicos estudam as possibilidades de recuperação da praia através de intervenções de engenharia costeira.

Sendo claro o processo erosivo em que a praia se encontra, este estudo teve como objetivo verificar a relação entre as características morfodinâmicas do sistema praial e a erosão instalada em especial no setor sul e central da Praia da Armação.

\section{Área de estudo}

A Praia da Armação está localizada no setor sudeste da Ilha de Santa Catarina (Figura 1). Esta região está exposta a cinco sistemas de ondas principais: ondulações de sudeste, ondulações de sul, vagas de leste, vagas de nordeste e vagas de sul (Araújo et al., 2003). Sendo que na primavera e verão a distribuição de ocorrência dos sistemas é uniforme e predominam condições de baixa energia, e no outono e inverno os predominam os picos do quadrante sul e sudeste com maior energia (Franco \& Melo Filho, 2008). Também há incidência de ondas de alta energia provenientes do quadrante E-ENE, durante as chamadas "lestadas", quando as ondas podem ultrapassar os 5 metros de altura, geralmente com menor período de pico que aquelas provenientes de S-SSE (Araújo et al., 2003).
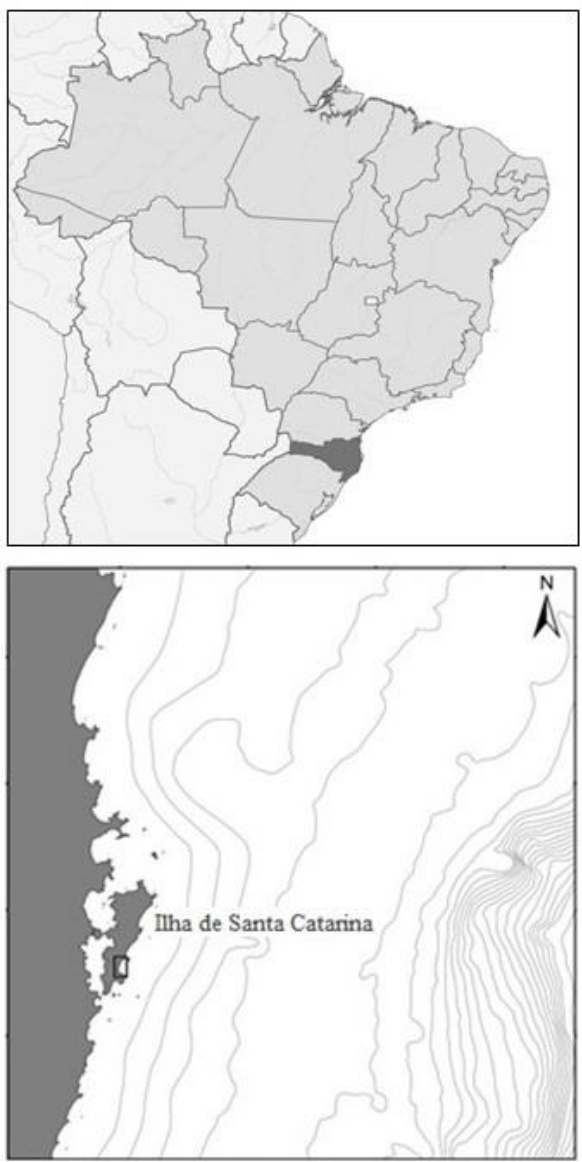

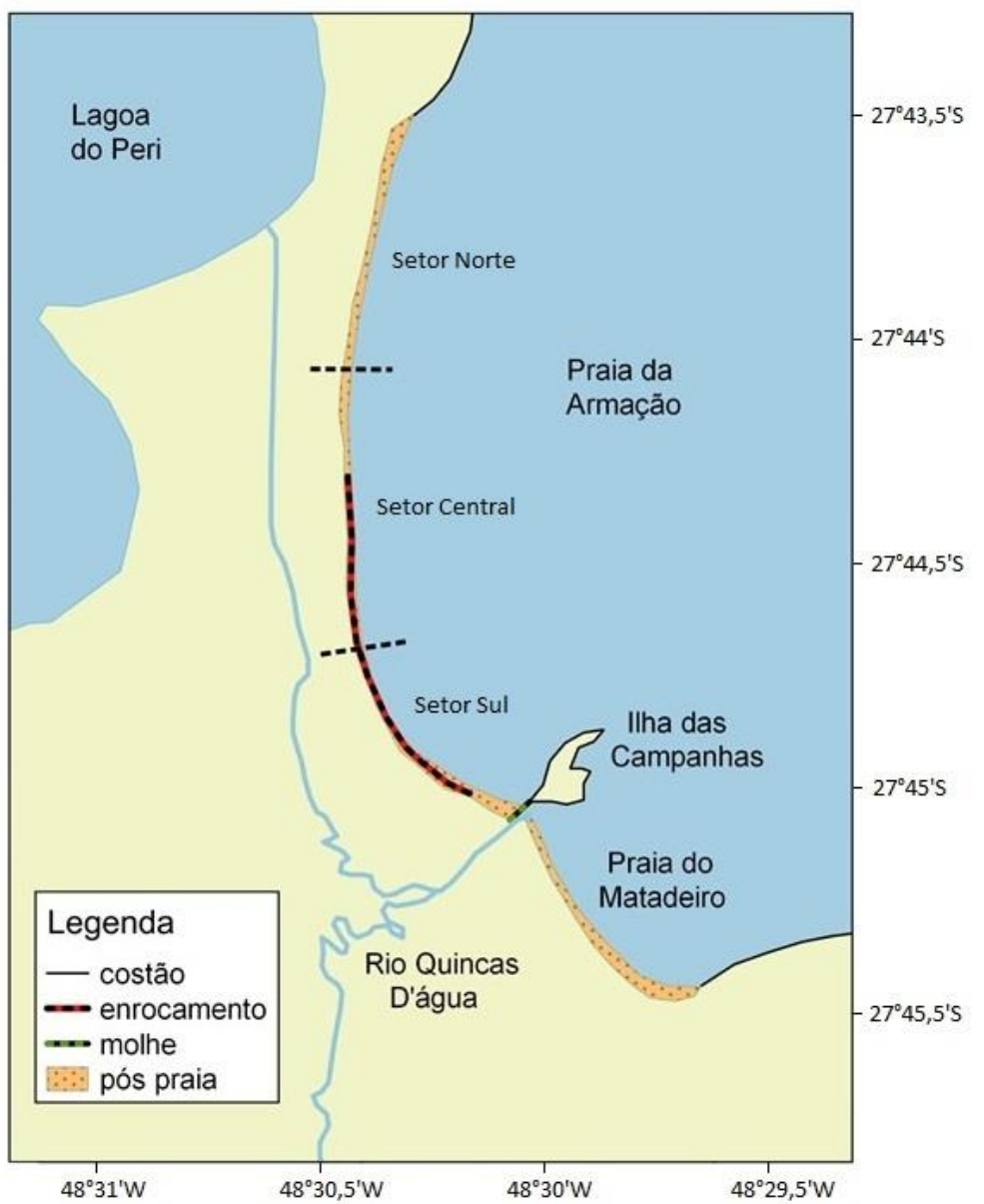

Figura 1- Localização da área de estudo e mapa esquemático da Praia da Armação indicando o enrocamento construído após eventos erosivos em 2010 e molhe que liga o extremo sul da praia a Ilha das Campanhas. As linhas tracejadas transversais à linha de costa delimitam os setores norte, central e sul.

Em seus 3500 metros de extensão, a Praia da Armação apresenta características morfodinâmicas distintas ao longo dos setores divididos em Norte, Central e Sul (Tabela 1). O setor norte é classificado como reflectivo, quanto ao seu estágio morfodinâmico, devido especialmente à sua granulometria de areia grossa e a declividade da face praial elevada (Abreu de 
Castilhos, 1995). Trata-se do setor mais energético da praia $(\mathrm{Hb}=1.30 \mathrm{~m})$, visto que recebe ondas tanto de E-ENE quanto de S-SSE. Esta alta energia associada ao elevado estoque sedimentar presente em sua porção aérea, faz com que a variação de volume subaéreo no setor norte seja duas vezes maior que o setor central e cinco vezes maior que o setor sul (Abreu de Castilhos, 1995). A pouca urbanização e a preservação da orla natural e da restinga neste setor permitem que as trocas sedimentares entres as porções da praia ocorram de forma natural sem interferências em seus diferentes períodos energéticos (Oliveira, 2009).

No setor central a praia é de energia de onda média $(\mathrm{Hb}=0.99 \mathrm{~m})$, sendo classificada também como refletiva (Abreu de Castilhos, 1995). Este trecho apresenta cúspides praias, correntes de retorno, sua granulometria é classificada como areia grossa e possui os maiores valores de declividade de face praial da enseada (Horn Filho, 2006). A orla deste trecho tem algumas casas localizadas próximas ao pós-praia
(Oliveira, 2009). No setor sul a praia é de baixa energia de onda $(\mathrm{Hb}=0.70 \mathrm{~m})$, pois é protegida das ondulações de sul e sudeste pela Ilha das Campanhas. Mas apesar de ser protegido da ação direta dessas ondas, o setor sul é constantemente invadido pelas correntes longitudinais geradas no sentido Norte-Sul (Oliveira, 2009). De granulometria fina, apresenta baixa declividade da face praial e seu estágio morfodinâmico é classificada como intermediário (Abreu de Castilhos, 1995).

Nesse setor a orla terrestre não possui dunas frontais, seu perfil é relativamente plano e possui intensa urbanização, estes fatores somados fazem com que este trecho seja classificado como de alto risco a erosão (Simó \& Horn Filho, 2004). Cabe destacar também neste setor o molhe construído na década de 40 e reestruturado na década de 70 com o objetivo de retificar o canal do Rio Quincas D'água. O molhe interrompeu a ligação, e provável troca de sedimentos, da praia da Armação com o rio Quincas D'água e com a praia do Matadeiro.

Tabela 1 - Características morfodinâmicas da Praia da Armação ao longo dos setores Norte, Central e Sul (adaptado de ${ }^{1}$ Abreu de Castilhos, 1995; ${ }^{2}$ Horn Filho, 2006; ${ }^{3}$ Oliveira, 2009).

\begin{tabular}{|c|c|c|c|c|}
\hline Características morfodinâmicas & Setor Norte & Setor Central & Setor Sul & Total \\
\hline Hb - Altura de quebra de onda (m) ${ }^{1}$ & 1.30 & 0.99 & 0.70 & 1.00 \\
\hline Diâmetro médio do grão (phi) ${ }^{2}$ & 0.13 & 0.22 & 2.07 & -- \\
\hline Classificação pelo diâmetro médio ${ }^{2}$ & Areia grossa & Areia grossa & Areia fina & -- \\
\hline Declividade da face praial $\left({ }^{\circ}\right)^{3}$ & 10.26 & 11.17 & 6.00 & 9.14 \\
\hline Valor de ômega $^{1}$ & 1.20 & 0.77 & 2.74 & 1.57 \\
\hline Classificação do estágio pelo ômega ${ }^{1}$ & reflectivo & reflectivo & intermediário & -- \\
\hline
\end{tabular}

\section{METODOLOGIA}

Inicialmente, para compreender melhor o processo erosivo instalado na praia, foi realizado um estudo de variação de linha de costa (VLC) e perfil de equilíbrio em planta. A caracterização morfodinâmica do sistema praial foi obtida através de estudos de granulometria, perfil praial (unificados no ítem morfologia praial) e clima de ondas. As etapas e métodos utilizados são descritos a seguir.

\section{Variação da linha de costa}

Para análise de variação da linha de costa da Praia da Armação ao longo das últimas décadas foram analisadas imagens dos anos de 1977, 1994, 2002, 2007 e 2009 (adquiridas junto ao Instituto de Planejamento Urbano de Florianópolis - IPUF e software Google Earth). Todas as imagens adquiridas foram georreferenciadas através do software ArcGIS 9.3, tendo como referência a Base Cartográfica 2007 do IPUF. Como estimador da linha de costa, optou-se por adotar o critério da Linha de Preamar Média (LPM), a qual é determinada pela linha de saturação hídrica nos sedimentos. A LPM representa uma boa opção como indicador de linha de costa por representar melhor as posições de máximas variações durante o dia da obtenção da aerofoto, minimizando erros de variações diurnas (Leatherman, 2001). As linhas de costa foram extraídas (digitalizadas) também pelo software ArcGis 9.3.

As taxas de Variação da Linha de Costa (VLC) foram calculadas utilizando a ferramenta computacional DSAS 3.2 (Digital Shoreline Analysis System). Para calcular a incerteza gerada no processo de extração das linhas de costa foram 
aplicadas as formulações propostas por Hapke et al. (2006):

$$
\begin{gathered}
E 1=\sqrt{e g^{2}+e d^{2}+e m^{2}} \\
E a=\frac{\sqrt{E 1^{2}+E 2^{2}}}{n}
\end{gathered}
$$

A primeira equação $(E 1)$ define que a incerteza gerada no processo de extração de cada linha de costa é dada pela raiz da soma dos quadrados das fontes dos erros individuais. Tais erros individuais são: $e g$ = erro de georreferenciamento; $e d=$ erro de digitalização da linha de costa; $\mathrm{em}=$ erro devido à variação da maré. A segunda equação $(E a)$ define a incerteza de forma anualizada entre duas ou mais linhas de costa. Onde $E 1$ é a incerteza da linha de costa no tempo "1", E2 é a incerteza da linha de costa no tempo "2" e $n$ é o tempo transcorrido em anos entre as linhas de costa " 1 " e " 2 ".

As análises dos resultados para Praia da Armação foram realizadas para praia como um todo, e para praia setorizada em Norte, Centro e Sul. Tal divisão foi feita pela praia apresentar características morfodinâmicas e processos de acresção e regressão da linha de costa bem distintos em cada trecho.

\section{Perfil de equilíbrio em planta}

Para avaliar o perfil de equilíbrio em planta da Praia da Armação foi escolhida a formulação da tangente hiperbólica (Moreno \& Kraus, 1999), já que a mesma simplifica o procedimento de ajuste $\mathrm{e}$ reduz a ambiguidade dos resultados oriunda da definição subjetiva do ponto de difração e/ou cristas de ondas predominantes. Esta análise contemplou o trecho côncavo da praia (setor sul, próximo ao promontório) e parte do setor retilíneo (central). A forma da tangente hiperbólica é definida em um sistema de coordenadas cartesianas relativo, como:

$$
y= \pm a \tanh ^{m}(b x)
$$

onde $y=$ distância através da costa; $x=$ distância ao longo da costa; e $a$ (unidades de comprimento), $b$ (unidades de comprimento-1), e $m$ (adimensional) são coeficientes determinados empiricamente. Para esta praia foram definidos os seguintes valores: $m=0.85, a=600$ e $b=0.00167$.

\section{Morfologia praial}

Foram realizadas 2 campanhas de levantamento de perfil praial subaéreo. A primeira (Campo I) ocorreu em fevereiro de 2012, e a segunda campanha (Campo II) foi realizada em maio de 2013. Os perfis foram extraídos com espaçamento de 300 metros entre eles, totalizando 10 perfis ao longo da praia (Figura 2). Ambos os levantamentos (Campo I e II) foram amarrados altimetricamente ao marco do Laboratório de Oceanografia Costeira (LOC - UFSC), localizado na Ilha das Campanhas. Como o marco utilizado estava referenciado a altitude geométrica, foi utilizado o programa MAPGEO 2010 - Modelo de Ondulação Geoidal, fornecido pelo IBGE, para conversão em altitude ortométrica. Tal modelo implica em uma incerteza de $\pm 0,32 \mathrm{~m}$.

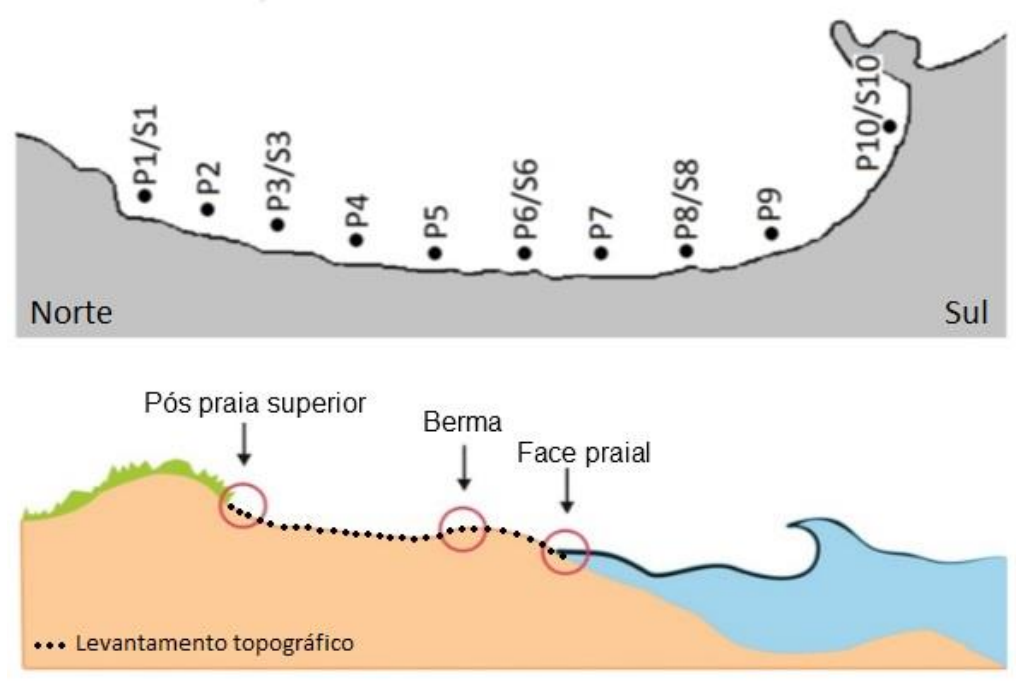

Figura 2 - Pontos do levantamento topográfico (P1 à P10) e da coleta de sedimentos (S1, S3, S6, S8 e S10) e indicação dos setores do perfil praial aonde foram coletadas as amostras de sedimentos.

As amostras de sedimento foram coletadas em maio de 2012. Os pontos de coleta de sedimentos foram definidos como subconjunto dos pontos do levantamento dos perfis subaéreos, resultando em
5 pontos ao longo da praia (Figura 3). Devido à elevada dinâmica do ambiente praial, foram coletadas amostras superficiais de sedimentos em três diferentes setores de cada perfil: pós-praia 
superior (PPS), berma e face praial, totalizando 15 amostras. Estas foram classificadas segundo a escala de tamanho de grão de Wentworth (1922), adaptada à escala phi $(\varnothing)$ por Krumbein (1934).

\section{Clima de ondas}

Dados de 30 anos de ondas (1980 - 2009) foram obtidos do modelo de reanálise Wave Watch 3 (WW3) em ponto na borda da grade regional
(Figura 3). Uma descrição detalhada da implementação do modelo, incluindo uma avaliação de desempenho do modelo na costa de Santa Catarina, pode ser encontrada em Melo et al. (2008). Os campos de saída do WW3 são paramétricos e as informações disponibilizadas utilizadas foram: altura significativa de onda $(\mathrm{Hs})$, período de pico (Tp) e direção de pico (Dp).
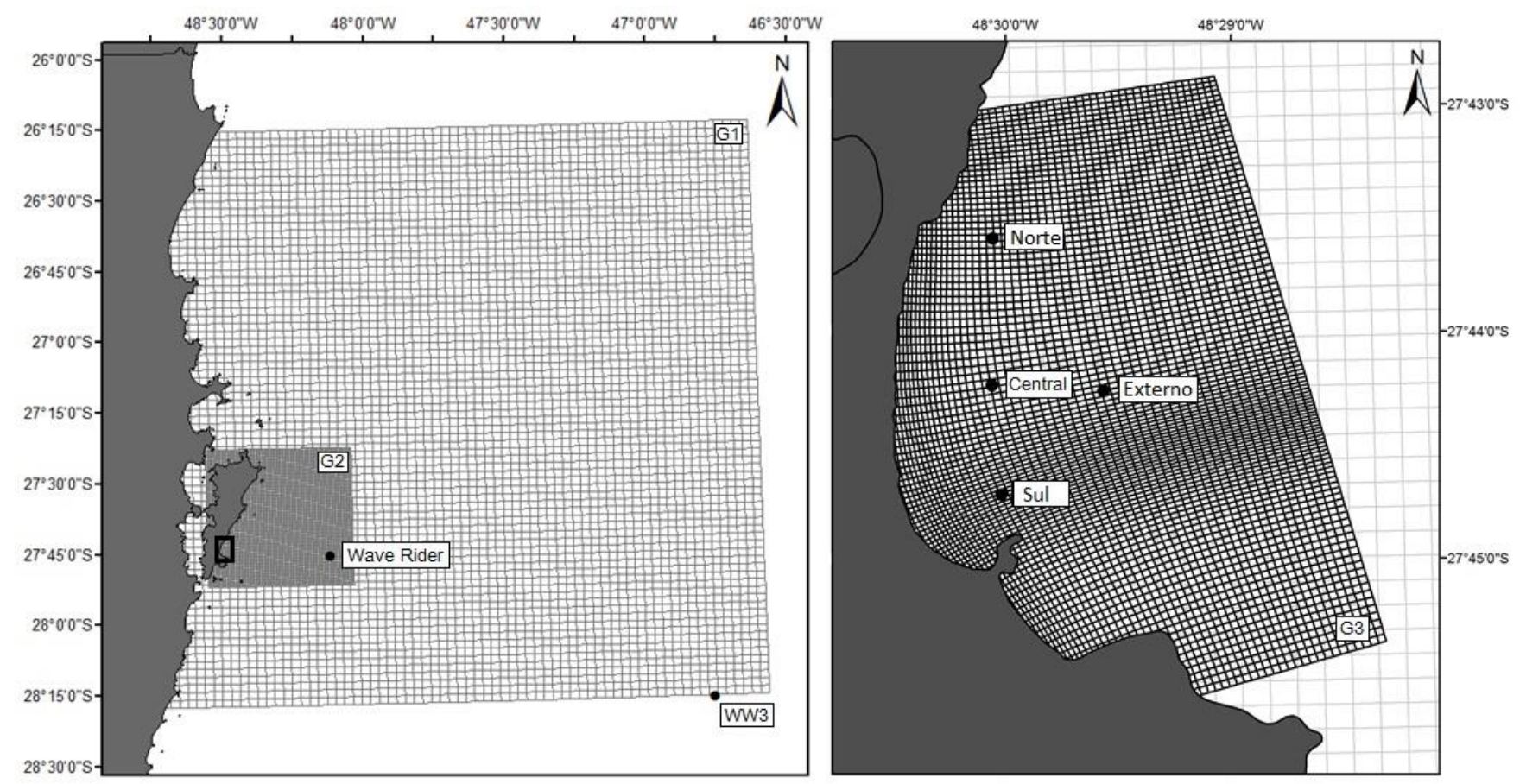

Figura 3 - Localização e abrangência das grades numéricas: regional (G1), intermediária (G2) e local (G3). E a localização dos seguintes pontos: WW3 (28 $15^{\prime} \mathrm{S}$ e $\left.46^{\circ} 45^{\prime} \mathrm{W}\right)$, fundeio do Wave Rider (27 $45^{\prime} 28^{\prime \prime} \mathrm{S}$ e $\left.48^{\circ} 07^{\prime} 00^{\prime \prime} \mathrm{W}\right)$ e pontos de reconstrução

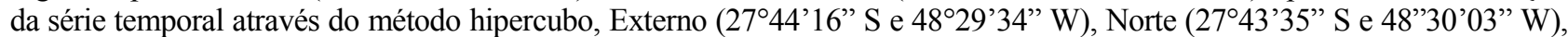

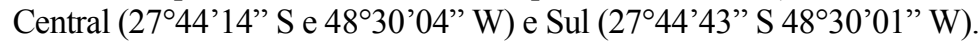

A fim de verificar a real atuação dos sistemas de ondas na área de estudo, a série temporal de 30 anos de dados de onda foi propagada de águas profundas até águas rasas na Praia da Armação. Este procedimento foi realizado utilizando o modelo numérico Delft3D-Wave (SWAN - Simulating Waves Nearshore; http://www.swan.tudelft.nl/) através do método do Hipercubo. Trata-se de uma técnica de amostragem estratificada na qual os estratos selecionados da distribuição são representados na amostra através de um representante (Mckay et al., 1979). O Instituto de Hidráulica da Universidade de Cantábria (IHCantabria) aplicou a técnica para criação de um método de transferência de séries de águas profundas para águas rasas que consiste em: i) selecionar os casos de ondas representativos em águas profundas; ii) propagar os casos selecionados de águas profundas para águas rasas e iii) reconstruir a série temporal em águas rasas por métodos de interpolação (Bonanata et al., 2010;
Camus et al., 2011). Para reconstrução da série temporal foi escolhido um ponto central em frente a área de estudo, em uma profundidade de 14,5 metros, e três pontos mais próximos à enseada distribuídos nos setores norte, central e sul (Figura 4).

A batimetria utilizada no modelo é uma composição de duas bases de dados: Cartas Náuticas fornecidas pelo Departamento de Hidrografia e Navegação (DHN) da Marinha Brasileira e medições batimétricas na porção sul da Praia da Armação realizado pelo Departamento de Edificações e Obras Hidráulicas de Santa Catarina $(\mathrm{DEOH})$ em 2009. As grades numéricas utilizadas são descritas abaixo:

- Grade regional: retangular com resolução regular de 1000 metros, abrange uma área de 48777 $\mathrm{km}^{2}$ e tem como limites o município de Itajaí ao norte, Imbituba ao sul e quanto ao limite oceânico a grade dista $190 \mathrm{~km}$ do continente na área de interesse; 
- Grade intermediária: retangular com resolução regular de 200 metros, compreende toda a Ilha de Santa Catarina;

- Grade local: compreende as praias da Armação e Matadeiro, com extensão máxima de $5,1 \mathrm{~km}$ na borda oeste. Possui resolução máxima de 17 metros na região sul da Armação e mínima de 31 metros na região oceânica da praia do Matadeiro.

Os dados de onda extraídos do modelo WW3 e o método de hipercubo foram validados com uma série de dados medidos por um ondógrafo (Wave Rider) fundeado (em torno de $35 \mathrm{~km}$ da costa e 80 metros de profundidade) pelo Laboratório de Hidráulica Marítima da Universidade Federal de

Santa Catarina (LaHiMar/UFSC). Os dados modelados apresentaram boa similaridade com os dos dados medidos (Figura 4), representando bem a distribuição dos sistemas de ondas que atuam na região. $\mathrm{O}$ pacote de dados modelados até águas rasas foram então analisados estatisticamente em sua totalidade e em blocos de dados de 10 anos, com o objetivo de identificar possíveis alterações nos padrões dos sistemas de ondas ao longo das décadas. A partir destes dados, foram extraídos também valores de Fluxo de Energia (taxa temporal de energia, em $\mathrm{J} / \mathrm{m}^{2}$, transferida de um local para o outro (Holthuijsen, 2007)):

$$
\text { Fluxo de energia }=0.45 H s^{2} \mathrm{Tp}
$$
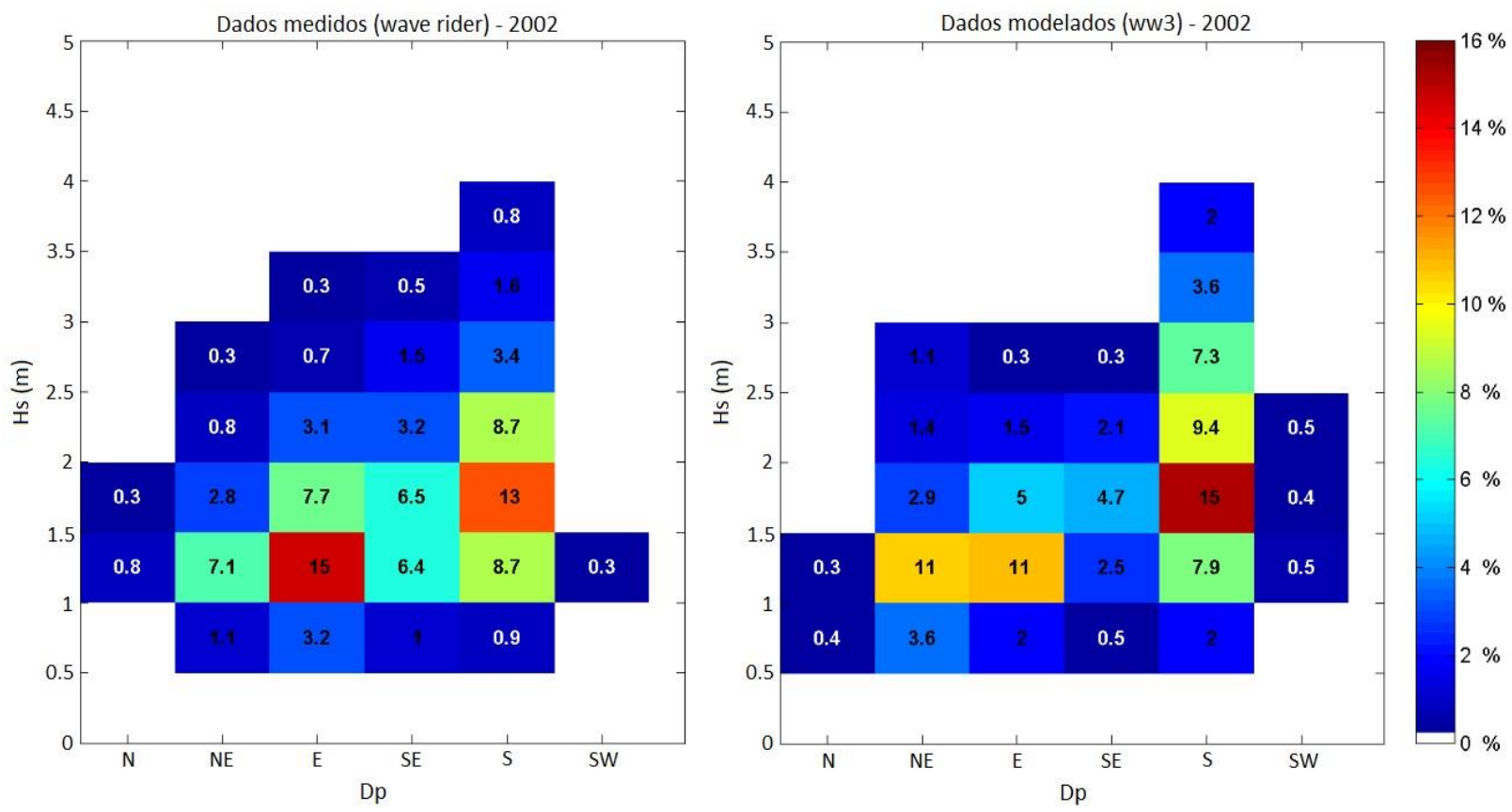

Figura 4 - Histogramas bivariados de altura significativa de onda (hs) por setores direcionais para os dados medidos (esquerda) e modelados (direta) para o ano de 2002.

\section{RESULTADOS}

Os resultados serão descritos seguindo as mesmas divisões aplicadas na metodologia: morfologia praial (para os resultados dos perfis praiais e análise granulométrica de sedimentos), clima de ondas, análise de variação de linha de costa e perfil de equilíbrio em planta.

\section{Variação da linha de costa}

A análise do deslocamento da linha de costa ao longo dos anos indicou 3 períodos com padrões distintos de variação de linha de costa (Tabela 2). O primeiro padrão refere-se ao período de 1977 à 1994 (década 80), onde a linha de costa sofre progradação no setor norte da praia (+6,55 m), e retração no setor central $(-15,51 \mathrm{~m})$ e sul $(-14,74 \mathrm{~m})$.
Verifica-se, portanto, que a resultante do transporte sedimentar para este período é de sul para norte, e parte do sedimento removido dos setores central e sul é realocado no pós praia do setor norte (Figura 5).

Para o período que segue, de 1994 à 2002 (década 90), verifica-se o padrão inverso encontrado no período anterior. Com o setor norte da praia sofrendo retração $(-6,89 \mathrm{~m})$ e os setores central $(+1,83 \mathrm{~m})$ e sul $(+11,13 \mathrm{~m}) \mathrm{em}$ processo de progradação da linha de costa. O que nos indica uma deriva litorânea de norte para sul, onde parte do estoque sedimentar removido do setor norte, provavelmente é depositado no setor central e principalmente no setor sul da praia. 
Tabela 2 - Valores de Deslocamento Total (metros) e Taxa de Variação (metros por ano) e suas incertezas, referente aos períodos de 1977 a 1994, 1994 a 2002 e 2002 a 2009.

\begin{tabular}{|c|c|c|c|c|c|c|c|c|}
\hline \multicolumn{9}{|c|}{ Deslocamento total $(\Delta d$ em m) e Taxa de variação ( $\Delta$ d/t em m/ano) } \\
\hline \multirow{2}{*}{ Setor } & \multicolumn{2}{|c|}{ 1977-1994 } & \multicolumn{2}{|c|}{ 1994-2002 } & \multicolumn{2}{|c|}{ 2002-2009 } & \multicolumn{2}{|c|}{$1977-2009$} \\
\hline & $\Delta \mathbf{d}$ & $\Delta \mathbf{d} / \mathbf{t}$ & $\Delta \mathbf{d}$ & $\Delta \mathbf{d} / \mathbf{t}$ & $\Delta \mathbf{d}$ & $\Delta \mathbf{d} / \mathbf{t}$ & $\Delta \mathbf{d}$ & $\Delta \mathbf{d} / \mathbf{t}$ \\
\hline Sul & -14.74 & -0.86 & 11.13 & 1,39 & $-19,71$ & $-2,82$ & -23.32 & -0.72 \\
\hline Central & -15.51 & -0.91 & 1.83 & 0,23 & $-2,56$ & $-0,37$ & -16.24 & -0.50 \\
\hline Norte & 6.55 & 0.38 & -6.89 & $-0,86$ & 12,43 & 1,78 & 12.09 & 0.37 \\
\hline Total & -7.99 & -0.47 & 2,30 & 0,29 & $-3,78$ & $-0,54$ & -9.47 & -0.29 \\
\hline Incerteza & \pm 2.27 & \pm 0.19 & $\pm 2,26$ & $\pm 0,40$ & $\pm 2,26$ &, \pm 46 & - & - \\
\hline
\end{tabular}

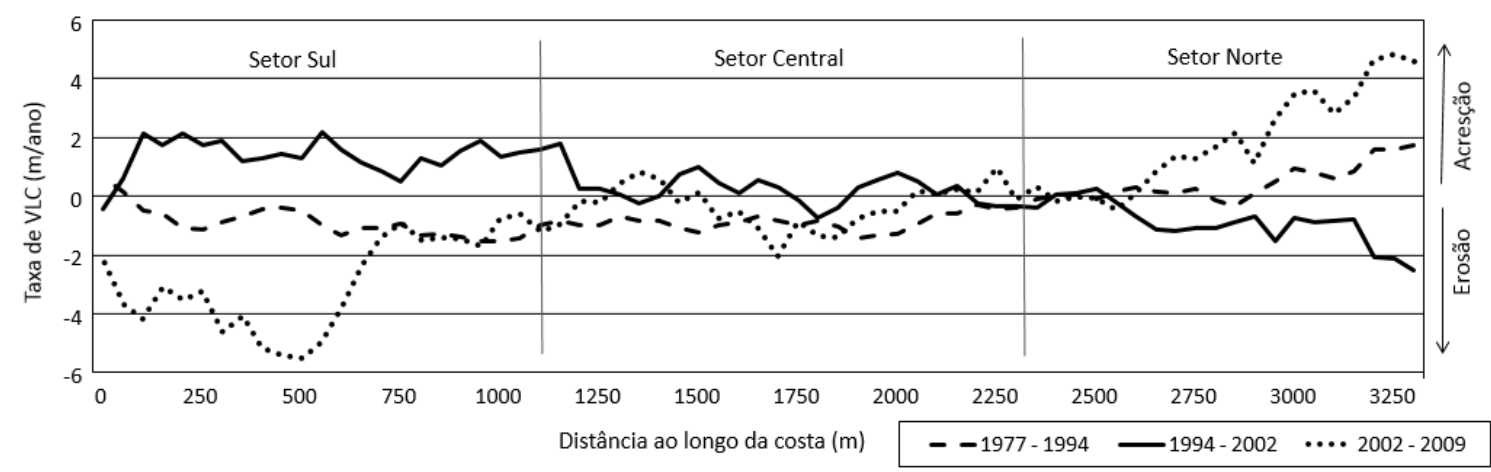

Figura 5 - Taxas de variação da linha de costa (m) para os períodos de 1977 à 1994, 1994 à 2002 e 2002 à 2009.

Para o último período, referente a década de 2000 (2002 à 2009), ocorre um processo de progradação $(+12,43 \mathrm{~m})$ no setor norte e retração do setor central $(-2,56 \mathrm{~m})$ e sul $(-19,71 \mathrm{~m})$. O que caracteriza, assim como no primeiro período, uma resultante no transporte sedimentar de sul. Perfil de equilíbrio em planta

Comparando a linha de costa de 2009 com a linha de costa teórica obtida com a aplicação do modelo foi possível caracterizar uma situação de equilíbrio dinâmico para o setor sul e equilíbrio estável para o setor norte (Figura 6). De 1900 metros de praias analisados, 800 metros de praia se encontra em processo de ajuste, remodelandose e buscando seu equilíbrio de acordo com os padrões energéticos e de balanço sedimentar.

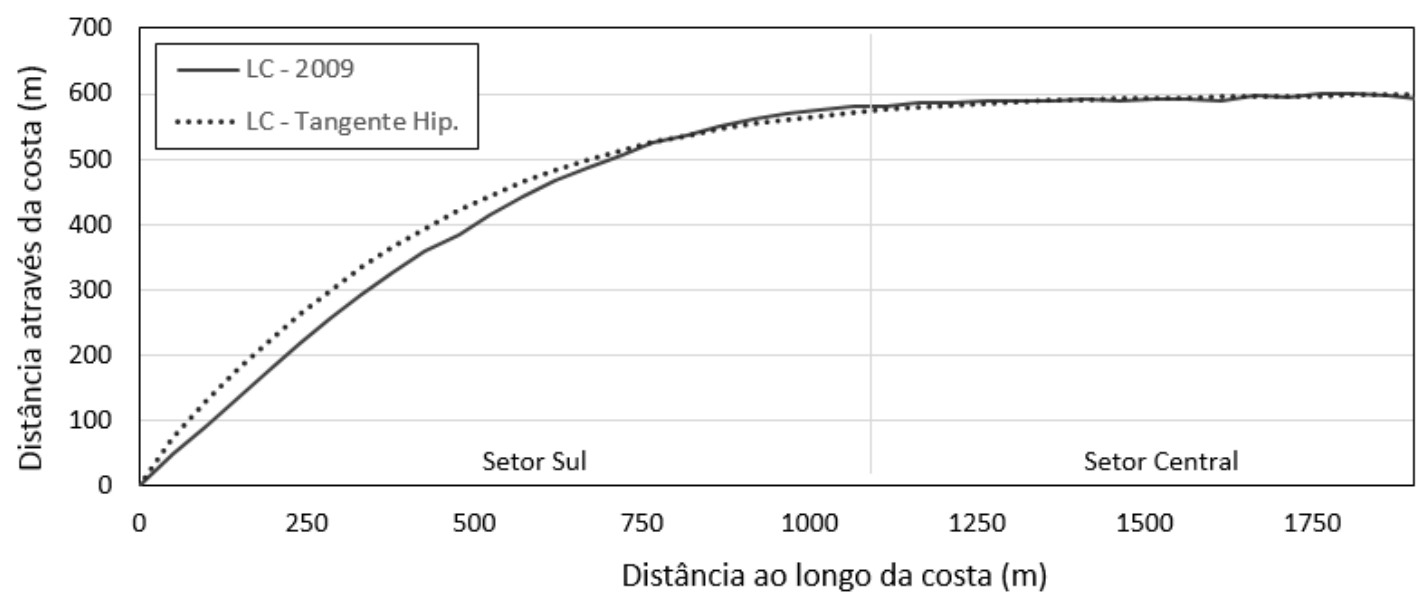

Figura 6 - Linha de costa de 2009 (sólida) e linha de costa teórica (pontilhada) obtida através da formulação de perfil de equilíbrio em planta proposto por Moreno \& Kraus (1999).

$\mathrm{O}$ modelo indica que o estado de equilíbrio estático será alcançado com a retração da linha de costa em grande parte do setor sul. Porém, a urbanização nesta região da praia é intensa e não respeita os limites de preservação de dunas, restinga e pós praia, impedindo que esse equilíbrio seja atingido.

\section{Morfologia praial}

Os dados dos perfis praiais (Figura 7) e granulometria (Figura 8) indicaram uma gradação lateral ao longo do arco praial. Com perfis mais inclinados e de areia grossa no setor norte, até perfis bem suaves de areia fina no setor sul. 

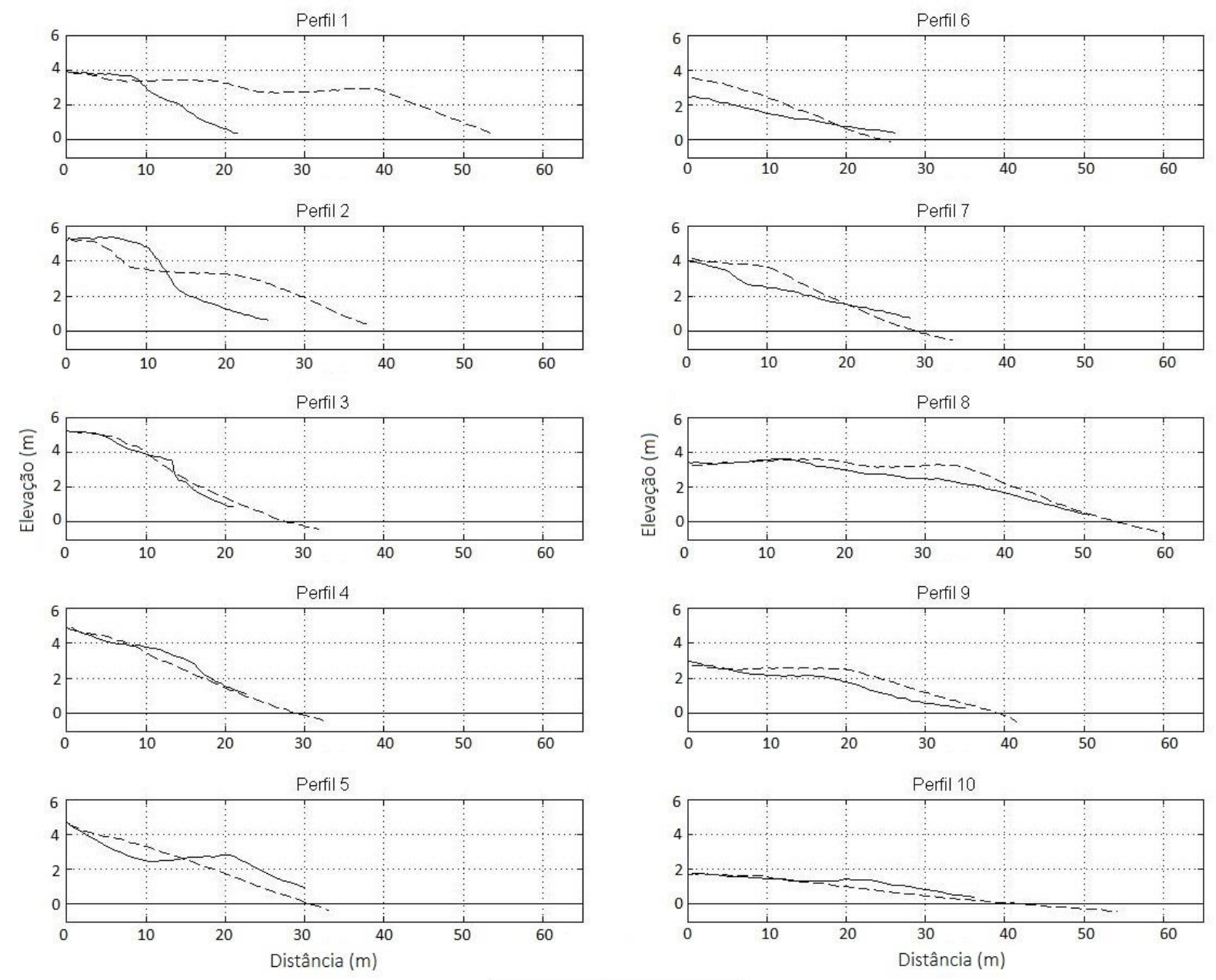

$2012----2013$

Figura 7 - Perfis praiais (1 à 10) obtidos em duas campanhas ao longo da praia da Armação.

O perfil praial 1, localizado no extremo do setor norte, apresentou altura máxima de 3,92 metros e um intenso processo de deposição sedimentar entre as campanhas, variando sua extensão de 22 a 53 metros. Possivelmente, esse incremento de volume sedimentar na porção emersa da praia foi resultado de um decaimento dos níveis energéticos entre os períodos.

Com a incidência de ondas mais baixas e menos esbeltas transportando novamente os sedimentos em direção à praia, fazendo os bancos migrarem até soldarem-se as mesmas. No Perfil 2, localizado 300 metros ao sul do anterior, verifica-se uma migração do pacote sedimentar subaéreo do pós praia superior para o pós praia inferior e face praial, também com um incremento de sedimentos. Possui altura máxima de 5,34 metros e sua extensão variou de 25 a 38 metros entre as campanhas. Ambos perfis $(01 \mathrm{e}$ 02) mostram uma praia com crista de berma bem pronunciada e alta declividade na face. É um setor de intensa variabilidade de forma.
Já os perfis 3 e 4 se mostraram mais estáveis que os anteriores, com pequenas variações de volume e forma entre as duas campanhas. Apresentaram altura máxima de $5,24 \mathrm{~m}$ e extensão de $28 \mathrm{~m}$. São perfis estreitos, muito inclinados e levemente côncavos. Perfis praiais mais côncavos são mais estáveis do que perfis mais retos, convexos ou irregulares. No Perfil 5, verifica-se na primeira campanha uma crista de berma com degrau bem definido. Posteriormente, ocorre uma migração do pacote sedimentar do pós praia inferior e face praial para o pós praia superior, resultando em um perfil praial mais retilíneo, com pouca alteração de volume. A altura máxima atingida pelo pacote sedimentar foi de $4,90 \mathrm{~m}$.

Nos perfis 6 a 9, parte do pós praia superior é suprimida pela estrutura de enrocamento. Nestes perfis observa-se um incremento do volume sedimentar do pós praia entre as campanhas. Os perfis 6 e 7, localizados no setor central da praia, são formados por areia muito grossa e grossa e 
são expostos à alta energia de ondas. Verifica-se que os perfis tiveram um aumento de declividade e passaram da forma convexa para côncava entre as duas campanhas. Tal variação é decorrente do incremento do volume sedimentar na praia aérea. Praias que sofrem erosão tendem a adquirir forma plana e convexa, enquanto uma praia que recebe um acréscimo de sedimento irá ficar mais íngreme e côncava.

Rumo ao sul, sob ação do sombreamento da Ilha das Campanhas, os perfis apresentaram maior extensão e menor declividade do que os anteriores. Os perfis 8 e 9 são semi-expostos, protegidos das ondas de S-SSE e expostos as de E-ENE. Com altura do pós praia entre 3,40 e 2,90 e extensão de 54 e $40 \mathrm{~m}$, apresentaram uma variabilidade média e crista de berma instável. O perfil 10 apresenta uma praia em rampa plana relativamente estável.

Esta morfologia é resultante da composição sedimentar de areia e muito fina e do setor ser abrigado da ação direta da alta energia das ondas, amplificada após a construção do molhe que uniu a planície costeira à Ilha das Campanhas. Os fenômenos de difração de ondas e sombreamento, somadas as características granulométricas, agem diretamente sobre a deposição e o transporte de sedimentos neste setor.

O que se verifica é que a forma e variabilidade dos perfis estão condicionadas ao nível energético do ambiente e tipo e abundância de sedimentos que compõem o sistema praial. Os perfis 01 e 02, compostos por areia grossa, possuem crista de berma bem pronunciada, e alta declividade na face. Foram os perfis que apresentaram maior variação de volume entre as duas campanhas. Indicativo da marcante sazonalidade e elevada altura de onda que atinge este setor. Os perfis 3 e 4, os mais inclinados de toda a praia, foram os que apresentaram maior estabilidade entre as campanhas. Já os perfis 5, 6 e 7, apresentaram amplitudes intermediárias de variação no volume de sedimentos. Pois apesar de localizados na zona mais exposta da praia, sua granulometria com tendência de areia muito grossa requerem uma elevada energia de onda para seu transporte. Chegando próximo ao setor sul da praia, os perfis 8 e 9 já apresentam maiores extensões e menores declividades que todos os anteriores, possuem a maior fração de areia média de toda a praia. No extremo sul, o perfil 10 é o mais plano, fato resultante da sua composição predominante por areia fina. A sua baixa variabilidade volumétrica entre as campanhas ocorre devido à proteção induzida pela Ilha das Campanhas.

Quanto a caracterização granulométrica, a análise das 15 amostras superficiais de sedimentos de praia permitiu constatar que o arco praial da Armação apresenta desenvolvida gradação lateral de tamanho de grão. No setor Norte da praia (amostras S1 e S3) a classe Areia Grossa representa $60 \%$, a Areia Muito Grossa $30 \%$, com as outras classes representando os $10 \%$ restantes (Figura 8). Já no setor Central (S6 e S8) ocorre o predomínio da fração Areia Muito Grossa (50\%), seguida de Areia Grossa (30\%), e já ocorrendo uma maior concentração de Areia Média (15\%). E no setor Sul a Areia Fina representa $64 \%$ dos sedimentos e a Areia Muito Fina $16 \%$.

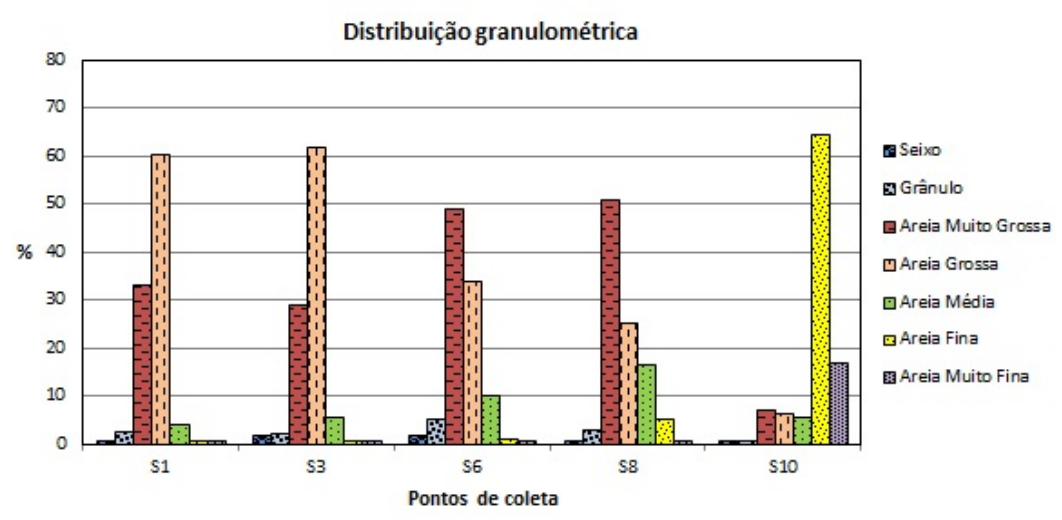

Figura 8. Distribuição granulométrica dos cinco pontos de coleta. Os valores são resultado da média obtida entre face, berma e pós praia superior.

\section{Clima de Ondas}

Para todo o período analisado (1980 à 2009; ponto externo), o clima de ondas na região de estudo apresentou uma altura significativa (Hs) mediana de $1,01 \mathrm{~m}$, tendo $70 \%$ das ocorrências com valores entre 0,5 e $1,5 \mathrm{~m}$. 
$\mathrm{O}$ período de pico (Tp) teve como predominante $(81 \%)$ os valores entre 6 e $12 \mathrm{~s}$ e uma mediana de $8,92 \mathrm{~s}$.
$\mathrm{E}$ as direções de pico mais atuantes foram as provenientes de lés-sudeste e lés-nordeste (Figura 9-A).

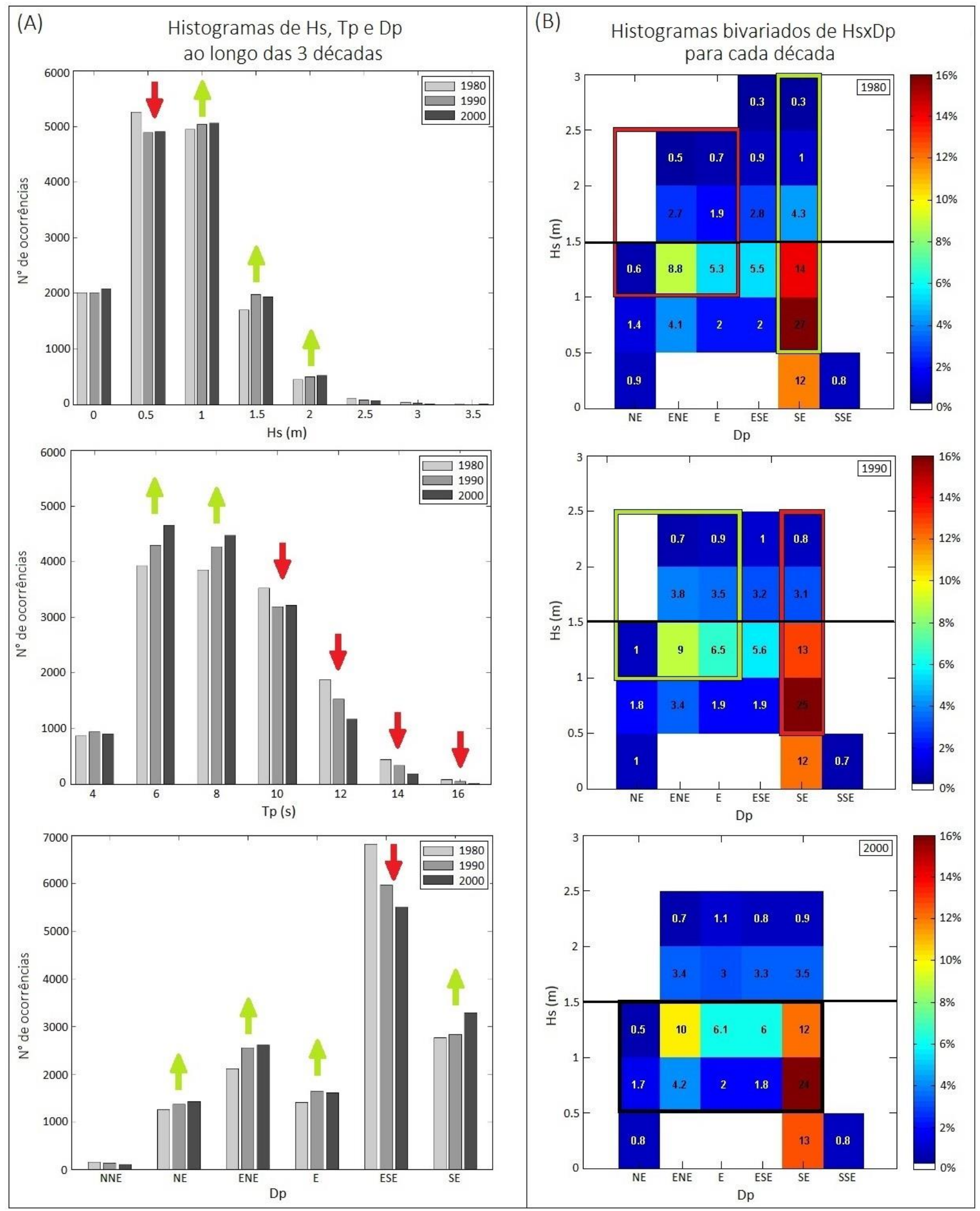

Figura 9 - Dados de onda extraídos do ponto externo. A) Histogramas de altura significativa (Hs em metros), período de pico (Tp em segundos), Direção de pico (Dp em graus) ao longo das três décadas; B) Histogramas bivariados de Hs por Dp para cada década.

Ao analisar os valores de $\mathrm{Hs}$, Tp, Dp para as comportamentos que merecem destaque: diferentes décadas, identificou-se os seguintes Período de pico (Tp): as ondas com 
períodos entre 6 e 8 segundos aumentaram progressivamente ao longo das três décadas. Enquanto que os períodos maiores, entre 10 e 16 segundos, diminuíram também progressivamente ao longo do tempo;

- Direção de pico (Dp): a ocorrência dos mares de NE, E e SE aumentou em detrimento dos mares de ESE. Esse aumento da frequência dos mares E e NE e diminuição dos mares de ESE podem explicar a diminuição na frequência dos mares de swell (ondas de alto período) e aumento dos mare locais (ondas de baixo período);

- $\quad$ Altura significativa (Hs): as ondas, com alturas superiores a $1,0 \mathrm{~m}$ aumentaram em número de ocorrência ao passar das décadas, logo a altura significativa média aumentou ao longo do tempo. Conforme mencionado nos itens anteriores, mesmo com a diminuição das ondas de maior período e de mares de SE que por característica possuem maior energia de ondas que os mares locais, a altura significativa continuou aumentando entre 1980 e 2009 . O que nos indica um incremento de energia nas ondas locais de NE e E.

Analisando apenas as ondas com altura significativa superior a 1,5 metros (Figura 9-B), observa-se que estas chegam até a praia da Armação nas classes direcionais lés-nordeste (ENE), leste (E) e lés-sudeste (ESE) e sudeste (SE).

E avaliando suas flutuações de ocorrência, verificou-se, inicialmente, um aumento no número de ocorrência ao longo das 3 décadas. Passando de 56,2 dias/ano na década de 80 a 62,1 dias/ano na década de 90, sofrendo pouca redução para 61 dias/ano na década de 2000.

A onda extrema de leste teve um aumento significativo de ocorrência da década de 80 para 90 , enquanto e a de sudeste diminuiu em proporção semelhante. Na década de 2000, a onda extrema de leste ocorreu em quantidade similar a década anterior, enquanto a de sudeste voltou a ocorrer com mais frequência.

Avaliando a ocorrência das ondas durantes os 30 anos em cada setor da praia (Figura 10), ficou clara a variação energética entre eles. No setor norte a onda mais ocorrente foi a de sudeste em todas as décadas (média de 52,07\% nos 30 anos). Já a segunda mais ocorrente variou, sendo a de lés-sudeste na década de $80(14,9 \%)$ e a de leste nas décadas de $90(16,5 \%)$ e $2000(15,6 \%)$. As ondas de leste foram também as que mais variaram neste setor nas 3 décadas, onde observou-se um aumento no número de ocorrência das ondas de média e alta energia. Em contra ponto, o setor como um todo teve um decréscimo na incidência das ondas de alta energia (acima de $12 \mathrm{~J} / \mathrm{m}^{2}$ ), 7,3\% em 1980, 6,2\% em 1990 e $5,8 \%$ em 2000.

Já no setor central verificou-se que a onda mais frequente chega até a praia no quadrante lés-sudeste, sofrendo uma forte variação entre as décadas de $80(67,7 \%), 90(62,7 \%)$ e 2000 $(70,6 \%)$. Seguida das ondas de lés-nordeste (que aumentaram sua ocorrência ao longo do tempo) e leste (com um pico de ocorrência na década de 90). Vale ressaltar que, ao contrário do setor norte, este setor teve um incremento das ondas de alta energia de 1,9\% em 1980 para 3,2\% em 1990, e 3,7\% em 2000.

No setor sul a onda mais frequente também atinge a praia de lés-sudeste (média de 60,6\%), porém sofreu forte redução em ocorrência e intensidade ao longo das décadas. Sendo então substituídas pelas ondas de lés-nordeste e leste que se intensificaram no período. E como no setor central, as ondas de alta energia tiveram maior ocorrência.

\section{DISCUSSÃO}

Os padrões morfológicos encontrados ao longo da Praia da Armação são comumente descritos em praias de enseada expostas a diferentes graus de energia de onda (Short, 1999). Na Ilha de Santa Catarina, a presença de areia de diferentes classes granulométricas é resultado da mistura entre sedimentos da planície costeira pleistocênica (areias finas) e sedimentos oriundos do retrabalhamento de rochas ígneas (areias grossas) trazidos até a praia em eventos de tempestade (Abreu de Castilhos, 1995;
Martins et al., 1970). E a forma como se distribuem ao longo da enseada é resultante da fonte do material e dos processos de deposição (King, 1972), onde o tamanho de grão e a declividade aumentam conforme a exposição da praia (Bascom, 1951). Como ocorre na Praia da Armação onde o material sedimentar mais grosso está associado a zonas de maior energia (setor norte e central), e a área com material mais fino (setor sul) a zonas de sombra de baixa energia. Além disso, as ondas mais energéticas que 
atingem a enseada são provenientes do quadrante leste (E) e lés-sudeste (ESE) e, portanto, transportam por deriva litorânea os sedimentos mais grosseiros para o setor norte. Enquanto que as ondas de nordeste, de baixa energia, conseguem transportar apenas frações menores para o sul. O setor sul ainda está localizado em área adjacente a desembocadura do Rio Quincas D’água, possível fornecedor também deste sedimento fino.
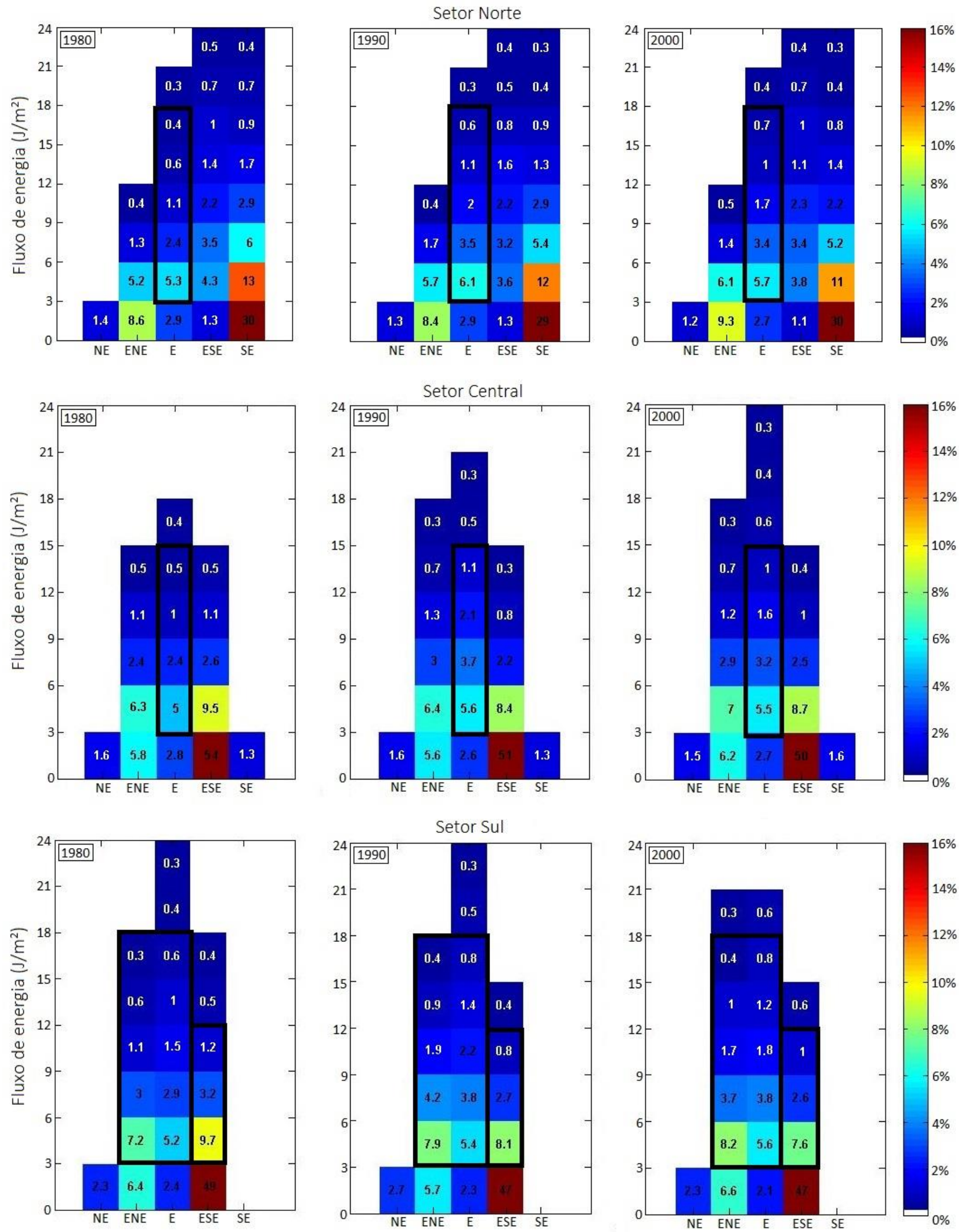

Figura 10 - Histogramas bivariados de fluxo de energia (Phy em $\mathrm{J} / \mathrm{m}^{2}$ ) por setores direcionais, analisados para os setores da praia (norte, central e sul). 
Essa variabilidade sedimentar e energética observada ao longo da praia consequentemente se reflete na forma com que o pacote sedimentar emerso é apresentado, e nas suas variações ao longo do tempo. Conferindo ao setor norte e central perfis com alta declividade, e ao setor sul perfis mais planos. A avaliação interanual dos perfis praiais emersos também indicou que a linha de costa no trecho norte da praia da Armação pode sofrer uma variabilidade de dezenas de metros em poucos meses. Enquanto os perfis do setor central e sul se mostraram mais estáveis, com variações de volume sedimentar subaéreo pequenos em um curto espaço de tempo. Entre os dois levantamentos topográficos (fev/2012 e mai/2013), no sistema praial como um todo, predominaram os processos de acresção sobre os de erosão entre as duas campanhas. Reafirmando assim a sazonalidade encontrada por Oliveira (2009) e Abreu de Castilhos (1995) para a enseada. Onde entre os meses de inverno e primavera (junho a novembro), com a intensificação dos sistemas frontais, ocorrem processos erosivos mais intensos. E durante os meses de verão e outono (dezembro a maio) a praia tende a maior acumulação.

A declividade, altura de onda, volume subaéreo, variação de linha de costa, altura da duna frontal, interferências antrópicas, dentre outras, são características comumente utilizadas em avaliações de suscetibilidade à erosão em praias arenosas (Gornitz et al., 1991; Bush, et al., 1999). Ao ser avaliada, a praia da Armação é comumente classificada como de alta suscetibilidade à erosão, em especial no setor sul por apresentar indícios de erosão intensa, estruturas de contenção, dunas frontais ausentes e perfil plano. Enquanto no setor norte e central a suscetibilidade é definida entre moderada e alta devido às altas taxas de variação da linha de costa (Rudorff \& Bonetti, 2010; Muler, 2012; Mazzer et al., 2008).

A linha de costa de uma praia torna-se estável quando alcança uma forma que se ajusta ao padrão de ondas refratado (Silvester \& Hsu, 1993). Já uma praia em equilíbrio dinâmico, em situação natural sem interferências antrópicas, terá ondas quebrando em um certo ângulo com a costa, gerando um transporte de sedimentos longitudinal (deriva litorânea) e consequentes alterações na linha de costa. As análises de variação de linha de costa indicaram uma linha de costa instável, com processos de progradação e retração alternados entre os períodos avaliados e os setores da praia. Esse comportamento sugere a ocorrência de um movimento lateral periódico de sedimentos. Na Praia da Armação o sistema de ondas de nordeste (Hs entre $0,5 \mathrm{~m} \mathrm{e} 1.0 \mathrm{~m} \mathrm{e}$ período médio de $6 \mathrm{~s}$ ) transporta sedimentos para sul a uma taxa de $28 \mathrm{~m}^{3} /$ dia. Já em condições de ondulação de sudeste (Hs entre 1,0 e 2,0 m e período médio de 10 segundos), a taxa de transporte sedimentar por deriva litorânea para norte é de $166 \mathrm{~m}^{3} / \mathrm{dia}, 5$ vezes maior (Abreu de Castilhos, 1997). Confrontando então as taxas de variação de linha de costa com as estatísticas decadais do clima de ondas, temos:

- Década de 1980: no primeiro período avaliado (1977-1994) observou-se um processo de progradação da linha de costa no setor norte $(+6,55 \mathrm{~m})$ e retração no setor central $(-15,51 \mathrm{~m})$ e sul $(-4,71 \mathrm{~m})$. O clima de ondas da década de 80 teve forte influência dos sistemas de ESE e $\mathrm{SE}$, e foi o único período em que ocorreu ondas a cima de $2,5 \mathrm{~m}$ vindas destes quadrantes. Tais ondulações, como indicado por Abreu de Castilhos (1997), transportam grandes volumes de sedimento de sul para norte;

- Década de 1990: no período seguinte (1994 - 2002, associado agora ao clima de ondas da década de 1990) a linha de costa apresentou variações contrárias ao anterior, com o setor central $(+1,83 \mathrm{~m})$ e sul $(+11,13 \mathrm{~m})$ da praia sofrendo progradação e o setor norte $(-6,89 \mathrm{~m})$ retração. Observou-se que da década de 80 para 90, as ondas de SE e ESE caíram em intensidade e número de ocorrências, enquanto as ondas de E, NE e ENE aumentaram também em ocorrência e intensidade. A ocorrência das ondas de ESE com altura superior a $1.5 \mathrm{~m}$ diminui fortemente enquanto o sistema de $\mathrm{E}$ assumiu a predominância neste período. Ou seja, ocorreu um incremento de energia no quadrante NE e E e um enfraquecimento do quadrante SE. Esse deslocamento possivelmente favoreceu a deriva litorânea de norte para sul, resultando no processo de retração encontrado no norte e progradação no setor central e sul;

- Década de 2000: no último período avaliado (2002 - 2009) o comportamento da linha de costa repete o padrão do primeiro período, com o setor central $(-2,56 \mathrm{~m})$ e sul ($19,71 \mathrm{~m}$ ) sofrendo retração e o norte progradação $(+12,43 \mathrm{~m})$. Nesse período o sistema de ondas de 
ESE voltou a se tornar representativo (em especial nos setores norte e central), porém ainda sem a influência encontrada na década de 80 . E as ondas que atingem o setor central e sul são as mais energéticas de todas as décadas analisadas.

Os resultados mostraram também que sistemas de ondas de menor período aumentaram em ocorrência ao longo das 3 décadas. Ondas de menor período sofrem menos refração e chegam com maior ânuglo a costa, sendo mais eficientes em gerar correntes longitudinais e consequentemente mudanças morfológicas (Muñoz-Pérez et al., 2010). Isto, associado ao aumento de ondas de alta energia (em especial no setor sul) aceleram as transformações morfológicas e tendem a deixar a linha de costa de praias de enseada mais curvas em suas periferias (Daly et al., 2011; Martins et al., 2010). Concordando assim com a linha de costa teórica obtida pela aplicação do modelo do perfil de equilíbrio em planta.

Porém, apesar de verificarmos essa relação entre os componentes morfológicos e hidrodinâmicos com as taxas de variação da linha de costa, o sistema praial como um todo apresentou uma retração de linha de costa de 0.29 m/ano (Tabela 2). O que indica que, além dos processos de realocação dos sedimentos entre os setores, o ambiente apresenta um déficit sedimentar. Este balanço sedimentar negativo possivelmente resulta da associação entre as características morfodinâmicas deste sistema, exploradas neste trabalho, e à duas intervenções antrópicas muito significativas: o molhe de estabilização do canal do Rio Quincas D’água e a ocupação desordenada no setor sul.

Sabe-se que a construção de um molhe em praia arenosa bloqueia parte da deriva litorânea, gerando uma progradação do lado a montante da deriva e retração a jusante (Vaidya et al., 2015).
$\mathrm{Na}$ Praia da Armação e sistemas praiais adjacentes à deriva litorânea residual é de sul para norte (Abreu de Castilhos et al., 1997; Silva et al., 2012).

O setor sul serve como fonte de sedimentos para o setor central e norte da praia e é abastecido pelos sedimentos provenientes da Praia do Matadeiro e Rio Quincas D'água. Portanto, o molhe interfere no ciclo da deriva litorânea dessa célula costeira, ocasionando assim uma perda de sedimentos crônica no setor sul da praia, que, por sua vez, resultará também em um déficit sedimentar nos setores central e norte. Dalbosco (2013) confirmou esta hipótese ao realizar estudos de modelagem hidrodinâmica e de transporte de sedimentos em cenário atual (com o molhe) e hipotético (sem o molhe). A autora verificou que no setor sul da Praia da Armação existe uma corrente fixa de sentido sul-norte para ambos cenários. Porém no cenário hipotético, na ausência do molhe, esta corrente sofre um incremento significativo de velocidade e de volume de sedimento transportado (em até 30\%) que varia de acordo com o sistema de onda incidente.

Associado a este déficit, a redução do suprimento de sedimentos ocasionado pela blindagem de parte do sistema praial pela urbanização, também interfere diretamente nos processos de auto-recuperação da praia após eventos de alta energia hidrodinâmica (Xue, 2009; Mallmann \& Pereira, 2014). O setor sul é o mais urbanizado da praia (Figura 11). Sua ocupação teve início na década de 80 e aos poucos tomou a direção da praia e se estabeleceu sobre áreas de restinga e dunas (Pereira, 2010). Tornando esta praia que é altamente suscetível à eventos de ressaca (Simó \& Horn Filho, 2004; Rudorff \& Bonetti, 2010) vulnerável também a processos erosivos.

\section{CONCLUSÕES}

Este artigo demonstrou que o conhecimento das características morfológicas e hidrodinâmicas, assim como seus padrões e alterações ao longo do tempo, são imprescindíveis para compreender os processos erosivos instalados em praias arenosas. Os resultados deste estudo indicaram que existe uma relação entre as características morfodinâmicas da Praia da Armação e suas taxas históricas de retração e progradação da linha de costa. Porém, a erosão instalada no setor central $(0.50 \mathrm{~m} / \mathrm{ano}) \mathrm{e}$ sul $(0.72 \mathrm{~m} / \mathrm{ano})$ da praia é resultado de um desequilíbrio no balanço sedimentar originado possivelmente de uma combinação de fatores, incluindo: i) ocupação intensa sobre área de duna e restinga, ii) bloqueio de entrada de sedimentos da Praia do Matadeiro e Rio Quincas D’água devido a construção do molhe ao sul da praia e iii) aumento na ocorrência de condições hidrodinâmicas que remobilizam sedimentos da 
zona aérea da praia e intensificam as correntes de deriva litorânea. Dada a sua alta sensibilidade às condições de alta energia de onda e de variação morfológica, a Praia da Armação precisa que seus mecanismos de autorregulação natural e a entrada de sedimentos sejam preservados e/ou recuperados.
Sugere-se que trabalhos futuros avaliem a funcionalidade e os impactos de medidas de recuperação praial.

E que estas contemplem entre os cenários estudados a retirada do molhe de fixação do canal Rio Quincas D'água e do enrocamento construído sobre o pós-praia.

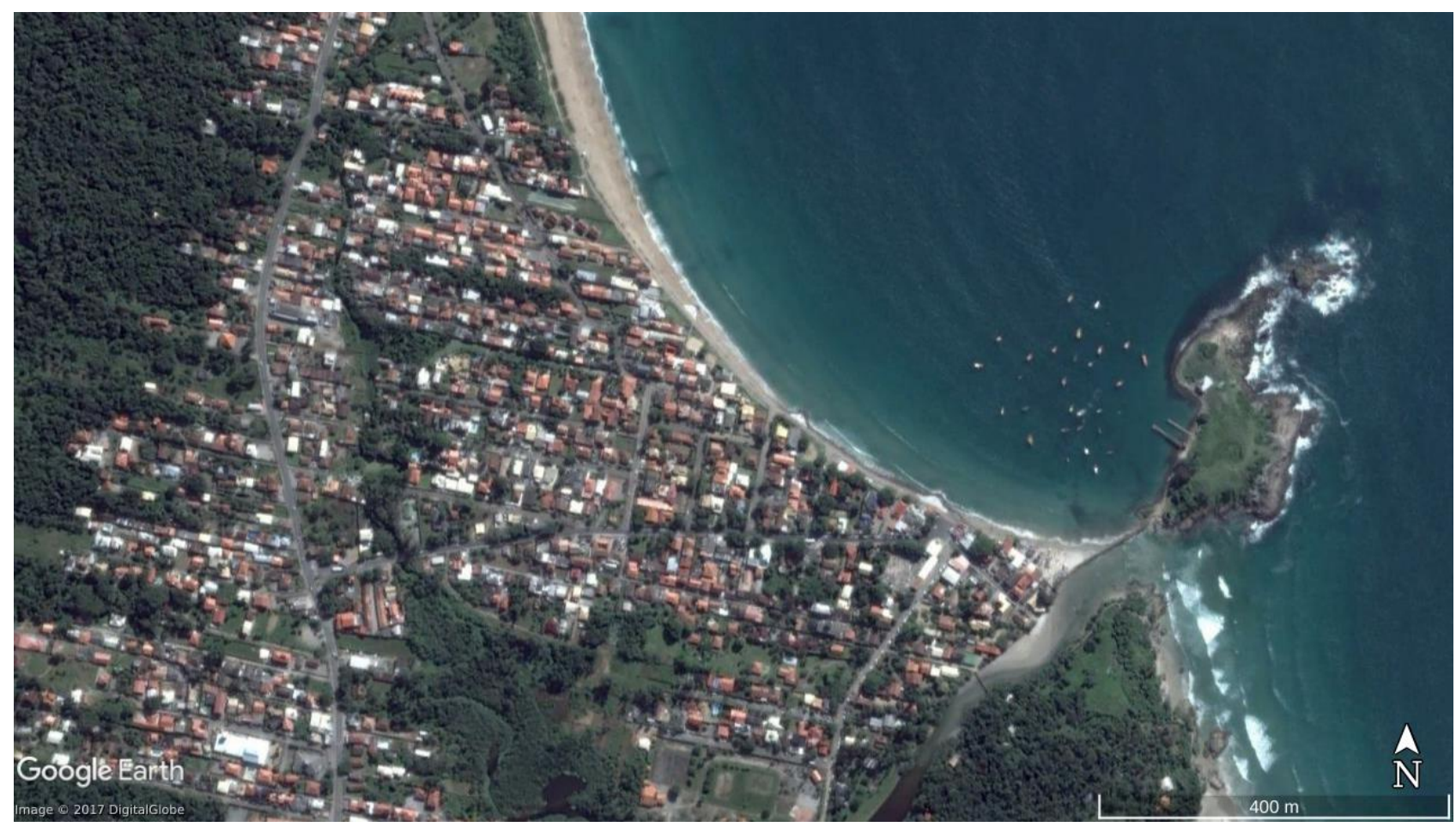

Figura 11 - Setor sul da Praia da Armação.

\section{REFERÊNCIAS}

ABREU DE CASTILHOS, J. Estudo evolutivo, sedimentológico e morfodinâmico da Praia da Armação, Ilha de Santa Catarina. Florianópolis, 1995. 134 p. Dissertação (Mestrado em Geografia) - Programa de Pós-Graduação em Geografia, Universidade Federal de Santa Catarina.

ABREU DE CASTILHOS, J. Morphodynamic and evolutive study of the Armação beach, Santa Catarina Island, Brazil. In: COLÓQUIO FRANCO - BRASILEIRO - MANEJO COSTEIRO DA ILHA DE SANTA CATARINA, 1997, Florianópolis. Resumos expandidos... Florianópolis: Universidade Federal de Santa Catarina, 1997, p. 227-228.

ABREU DE CASTILHOS, J. 2010. Evolução dos processos erosivos na praia da armação, Ilha de SC, entre 1990 e 2010. In: CONGRESSO BRASILEIRO DE GEOLOGIA, 45, 2010, Belém. Resumos expandidos...Belém: Sociedade Brasileira de Geologia, 2010, p. 388.

ABREU DE CASTILHOS, J.; GRE, J.C.R.; HORN FILHO, N.O. Ocupação urbana da orla nas praias oceânicas da Costa Leste da Ilha de Santa Catarina: riscos de erosão costeira. In: $11^{\circ}$ CONGRESSO BRASILEIRO DE GEOLOGIA DE ENGENHARIA E AMBIENTAL - ABGE, 2005, Florianópolis. Resumos expandidos...Florianópolis: Universidade Federal de Santa Catarina, 2005, p. 1231-1242.

ARAÚJO C.E.S., FRANCO D., MELO FILHO E., PIMENTA F. Wave regime characteristics of southern Brazilian coast. In: International Conference on Coastal and Port Engineering in Developing Countries, 2003, Colombo, Sri Lanka. Resumos expandidos... Colombo: COPEDEC, Paper No .97, 15p.

BASCOM, W.N. The relationship between sand-size and beach face slope. Transactions, American Geophysical Union, v. 32, p. 866-874, 1951

BONANATA, R.; MEDINA, R.; SILVEIRA, L.; BENEDET, L. Metodología para la Caracterización del Clima Maritimo em un Punto Cerca de la Costa a Partir de una Serie de Datos em Aguas Profundas. In: VI Congreso Argentino de Ingeniería Portuaria, 2010, Argentina. Resumos expandidos...Argentina: Associación Argentina de Ingenieros Portuarios, 2010, p. 1-14. BUSH, D.M.; NEAL, W.J.; YOUNG, R.S.; \& PILKEY, O.H. Utilization of geoindicators for rapid assessment of coastalhazard risk and mitigation. Ocean Coastal Management, v. 42, n. 8, p. 647-670, 1999.

CAMUS, P.; MENDEZ, F. J.; MEDINA, R. A hybrid eficiente method to downscale wave climate to coastal areas. Coastal Engineering, v. 58, p. 851-862, 2011

DALBOSCO, A.L.P. Análise histórica da linha de costa e dos padrões hidrodinâmicos e de transporte de sedimentos da Praia da Armação, Ilha de Santa Catarina. Florianópolis, 2013. 209 p. Dissertação (Mestrado em Engenharia Ambiental) - Programa de Pós-Graduação em Engenharia Ambiental, Universidade Federal de Santa Catarina.

DALY, C.J.; BRYAN, K.R.; ROELVINK, J.A.; KLEIN, A.H. F.; HEBBELN, D.; WINTER, C. Morphodynamics of embayed beaches: the effect of wave conditions. Journal of Coastal Research, v. 64, p. 1003-1007, 2011.

FRANCO, D. \& MELO FILHO, E. Relevância dos mares secundários na caracterização do regime de ondas ao largo da Ilha de Santa Catarina, SC (2002 2005). In: III Seminário e workshop em Engenharia Oceânica, 2008, Rio Grande. 
Resumos expandidos... Rio Grande: Programa de PósGraduação em Engenharia Oceânica - Universidade Federal do Rio Grande, p. 1-20.

GORNITZ, V.M.; WHITE, T.W.; CUSHMAN, R.M. Vulnerability of the US to future sea level rise. Coastal Zone. In: Proceedings of the 7th Symposium on Coastal and Ocean Management, 1991, Long Bech. Resumos expandidos...Long Beach: American Society of Civil Engineers, 1991, p. 1345-1359.

HAPKE, C. J.; REID, D.; RICHMOND, B. M.; RUGGIERO, P.; LIST, J. Historical Shoreline Changes and Associated Coastal Land Loss Along the Sandy Shorelines of the California Coast. In: U.S. Geological Survey (Coordenador), National assessment of shoreline change. Reston: U. S. Geological Survey Open-file Report, 72 p., 2006.

HOLTHUIJSEN, L. H. (Coord.). Waves in Oceanic and Coastal Waters. Cambridge: University Press, 387 p., 2007.

HORN FILHO, N. O. Granulometria das praias arenosas da ilha de Santa Catarina, SC. Gravel, v. 4, p. 1-21, 2006.

KING, C. (Coord.). Beaches and Coasts. London: Edward Arnold, 570 p., 1972.

KRUMBEIN, W.C. Size frequency distribution of sediments. Journal of Sedimentary Petrology, v. 4, p. 65-77, 1934.

LEATHERMAN, S. Social and Economic Costs of Sea Level Rise. In: DOUGLAS, B.C.; KEARNEY, M.S., LEATHERMAN, S.P. (Coords), Sea Level Rise History and Consequences. San Diego: Academic Press, 232 p., 2001.

MALLMANN, D.L.B. \& PEREIRA, P.S. Coastal erosion at Maria Farinha Beach, Pernambuco, Brazil: possible causes and alternatives for shoreline protection. Journal of Coastal Research, v. 71, p. 24-29, 2014.

MARTINS, C.C.; DE MAHIQUES, M.M.; DIAS, J.M.A. Daily morphological changes determined by high-energy events on an embayed beach: a qualitative model. Letters to Earth Surface Processes and Landforms, v. 35, p. 487-495, 2010.

MARTINS, L.R.; GAMERMANN, N.; SCHEIBE, L.F.; TEIXEIRA, V. H. Sedimentologia da Ilha de Santa Catarina areias praiais. Boletim da Escola de Geologia, Publicação Especial, 18, p. 1-55, 1970.

MAZZER, A.M.; DILLENBURG, S.R.; SOUZA, C.RG. Proposta de método para análise de vulnerabilidade à erosão costeira no sudeste da Ilha de Santa Catarina, Brasil. Revista Brasileira de Geociências, v. 38, n. 2, p. 278-294, 2008.

MCKAY, M.D., BECKMAN, R.J., CONOVER, W.J. A Comparison of Three Methods for Selecting Values of Input Variables in the Analysis of Output from a Computer Code. Technometrics, v. 21, n. 2, p. 239-245, 1979.

MELO, E.F.; HAMMES, G.R.; FRANCO, D.; ROMEU, M.A.R. Avaliação de desempenho do modelo WW3 em Santa Catarina. In: III Seminário e workshop em Engenharia Oceânica, 2008, Rio Grande. Resumos expandidos...Rio Grande: Programa de Pós-Graduação em Engenharia Oceânica - Universidade Federal do Rio Grande, 20 p.
MORENO, L. \& KRAUS, N. Equilibrium shape of headland-bay beaches for engineering design. Proc. Coastal Sediments, ASCE, p. 860-875, 1999.

MUEHE, D. (Coord.). Erosão e Progradação do Litoral Brasileiro. Brasília: MMA. 9 p., 2006.

MULER, M. Avaliação da vulnerabilidade de praias da Ilha de Santa Catarina a perigos costeiros através da aplicação de um índice multicritério. Florianópolis, 2012. 213 p. Dissertação (Mestrado em Geografia) - Programa de Pós Graduação em Geografia, Universidade Federal de Santa Catarina.

MUÑOZ-PÉREZ, J.J.; CABALLERO, I.; TEJEDOR, B.; GOMEZ-PIÑA, G. Reversal in longshore sediment transport without variations in wave power direction. Journal of Coastal Research, v. 26, n. 4, p. 780-786, 2010.

OLIVEIRA, U.R. Relações entre a morfodinâmica e a utilização em trechos da costa oceânica da Ilha de Santa Catarina, SC, Brasil. Florianópolis, 2009, 222 p. Tese (Doutorado em Geografia) - Programa de Pós-Graduação em Geografia, Universidade Federal de Santa Catarina.

PEREIRA, E. P. P. Praia da Armação: uma análise das causas e efeitos dos danos provocados em maio de 2010 . Florianópolis, 2010. 129 p. Trabalho de Conclusão de Curso (Bacharel em Geografia) - Graduação em Geografia, Universidade do Estado de Santa Catarina.

RUDORFF, F. M. \& BONETTI, J. Avaliação da suscetibilidade à erosão costeira de praias da Ilha de Santa Catarina. Brazilian Journal Aquatic Science Technology, v. 14, n. 1, p. 9-20, 2010.

SILVA, G.M.; MOUSAVI, S.M.S.; JOSÉ, F. Wave-driven sediment transport and beach-dune dynamics in a headland bay beach. Marine Geology, v. 323-325, p. 29-46, 2012.

SILVESTER, R. \& HSU, J.R.C. (Coords). Coastal Stabilization: Innovative Concepts. Englewood Cliffs: PTR Prentice Hall, Inc., 327 p., 1993.

SIMÓ, D.H. \& HORN FILHO, N.O. Caracterização e distribuição espacial das "ressacas" e áreas de risco na Ilha de Santa Catarina, SC, Brasil. Gravel, v. 2, p. 93-103, 2004.

SHORT, A. (Coord.). Handbook of beach and shoreface morphodynamics. Chichester: John Wiley \& Sons, Inc., 379 p., 1999.

VAIDYA, A.M.; KORI, S. K.; KUDALE, M.D. Shoreline Response to Coastal Structures. Aquatic Procedia, 4, 333-340, 2015.

XUE, Z.; FENG, A.; YIN, P.; XIA, D. Coastal erosion induced by human Activities: a Northwest Bohai Sea case study. Journal of Coastal Research, v. 25, n. 3, p. 723- 733, 2009.

WENTWORTH, C.K. A scale of grade and class term for clastic sediments. Journal of Geology, v. 30, p. 377-392, 1922

Submetido em 2 de agosto de 2017 Aceito em 4 de outubro de 2018 